\title{
EDITORIAL
}

\section{Micronutrient deficiency in the aetiology of obesity}

International Journal of Obesity (2010) 34, 947-948;

doi:10.1038/ijo.2010.81

Despite the fact that the positive energy balance equation is very simple, the promoters that produce a positive energy balance are complex and poorly understood. We have observed that the obesity epidemic seems to have reached a plateau in several countries, ${ }^{1,2}$ but the reason for this is essentially unknown. It is now fully recognized that it is far too simplistic to believe that interventions such as smaller portions sizes, low-energy-density foods and more physical activity are sufficient to prevent obesity. Recent research has revealed many putative aetiological factors such as impaired sleep, mental stress, television viewing, and dietary factors such as energy from sugar in soft drinks and insufficient intake of certain nutrients such as protein ${ }^{3}$ or calcium. $^{4}$

Micronutrient deficiencies have been observed in obese individuals in many parts of the world, and it is obvious that these may influence several physiological body functions, impair the immune system and increase the risk of comorbidities. ${ }^{5}$ Whether they may also promote a positive energy balance and contribute to maintenance of the obese state is less well understood. There are clear associations between micronutrient deficiencies and obesity in various populations, and there is evidence to suggest that such deficiencies can affect leptin and insulin metabolism. However, there are multiple pathways by which a micronutrient deficiency could impair appetite regulation and energy metabolism, and these areas are poorly investigated in relation to human energy balance and obesity. Micronutrient deficiency in obesity may not be due to only inadequate intakes, but also due to changed metabolism and excretion. The complexity of the question is increased by the uncertainty as to how to assess and define the optimal status of vitamins, minerals and trace elements in obese individuals.

Major et al. ${ }^{6}$ found that consumers of dietary vitaminmineral supplements, after proper adjustments for confounding factors, were leaner and had lower body fat than non-consumers. In a second randomized, placebo-controlled study they assessed the effect of a multivitamin-mineral supplement versus placebo, combined with an energyrestricted diet, on appetite and body weight in a 15-week study. ${ }^{6}$ They found no significant effect on body weight or body fat, but the vitamin-mineral supplement had a beneficial effect on appetite regulation. These studies suggest that vitamin-mineral status might have a role, but also suggest that future studies should enrol obese individuals with low vitamin-mineral status, and the studies should be powered to detect even small differences in body fat changes.

In this issue of the International Journal of Obesity Li et al. ${ }^{7}$ report a Chinese randomized, controlled 26-week intervention study comparing a 29-ingredient multivitamin and mineral supplementation with a low-calcium $(162 \mathrm{mg}$ per day) dietary supplement, and with placebo. They found that the micronutrient supplementation produced significant reductions in body weight and fat mass, waist circumference, blood pressure and increased resting energy expenditure, and also had a positive effect on lipid profiles, whereas calcium supplementation alone produced only a beneficial effect on blood lipids. The weight loss was $3.6 \mathrm{~kg}$ in the vitamin-mineral supplemented group versus $1.1 \mathrm{~kg}$ in the calcium, and $0.2 \mathrm{~kg}$ in the placebo group.

The results are intriguing as they suggest that vitaminmineral supplementation, at least in Asians, may contribute to a clinically relevant weight loss of the same order as pharmacological agents like orlistat. It seems too good to be true, but we find the study to be of good quality and with no apparent flaws. It is possible that the positive effect of the supplement could be a matter of chance and the trial definitely needs to be replicated before the outcome can the translated into any public health message conveying the advice that insufficient intakes of micronutrients may lead to weight gain and that supplementation may be used as a weight loss remedy.

The study by Li et al. does not actually suggest that the participants were micronutrient deficient. The results presented in Table 3 of the article ${ }^{7}$ suggest that the dietary micronutrients intake of the study group before the study was either in accordance with or higher than recommendations. However, the current recommendations are calculated for normal weight, healthy persons. A chain is no stronger than the weakest link, and the data for intake of micronutrients do not cover all essential micronutrients. Vitamin D, for example, might be essential for normal metabolism, and recent evidence suggests that inadequate levels of vitamin D may promote weight gain, obesity and the metabolic syndrome. ${ }^{8}$ Intake of vitamin D is not given in the present article, nor is there any discussion as to whether 
the participants' production of vitamin D from exposure to the sunlight may be sufficient.

In conclusion, the prospect that micronutrient supplementation may be important for body weight regulation is timely in an environment where few weight loss compounds are available, and more approved compounds are being removed from the marked (for example, rimonabant and sibutramine) than new ones are coming in. We would welcome other well-designed, randomized, placebocontrolled studies that examine the effect of micronutrient supplementation targeting various groups regarding age, gender, degree of obesity and ethnicity.

\section{Conflict of interest}

The authors declare no conflict of interest.

A Astrup and S Bügel

Faculty of Life Sciences, Department of Human Nutrition, University of Copenhagen, Frederiksberg, Denmark

E-mail: ast@life.ku.dk

\section{References}

1 Lissner L, Sohlström A, Sundblom E, Sjöberg A. Trends in overweight and obesity in Swedish schoolchildren 1999-2005: has the epidemic reached a plateau? Obes Rev 2009. E-pub ahead of print 16 December 2009; doi: 10.1111/j.1467-789X.2009.00696.x.

2 Flegal KM, Carroll MD, Ogden CL, Curtin LR. Prevalence and trends in obesity among US adults, 1999-2008. JAMA 2010; 303: 235-241.

3 Paddon-Jones D, Westman E, Mattes RD, Wolfe RR, Astrup A, Westerterp-Plantenga M. Protein, weight management, and satiety. Am J Clin Nutr 2008; 87: 1558S-1561S.

4 Major GC, Chaput JP, Ledoux M, St-Pierre S, Anderson GH, Zemel $\mathrm{MB}$ et al. Recent developments in calcium-related obesity research. Obes Rev 2008; 5: 428-445.

5 García OP, Long KZ, Rosado JL. Impact of micronutrient deficiencies on obesity. Nutr Rev 2009; 67: 559-572.

6 Major GC, Alarie FP, Doré J, Tremblay A. Calcium plus vitamin D supplementation and fat mass loss in female very low-calcium consumers: potential link with a calcium-specific appetite control. Br J Nutr 2009; 101: 659-663.

7 Li Y, Wang C, Zhu K, Feng RN, Sun CH. Effects of multivitamin and mineral supplementation on adiposity, energy expenditure and lipid profiles in obese Chinese women. Int J Obes 2010; 34: 1070-1077.

8 Reis JP, von Mühlen D, Miller ER, Michos ED, Appel LJ. Vitamin D. Pediatrics 2009; 124: e371-e379. 